\title{
Measurement noise as a component of uncertainty measurements of the surface texture
}

\author{
TOMASZ DOBROWOLSKI \\ JAN TOMASIK \\ KATARZYNA TANDECKA \\ MAREK MAGDZIAK \\ RAFAŁ REIZER *
}

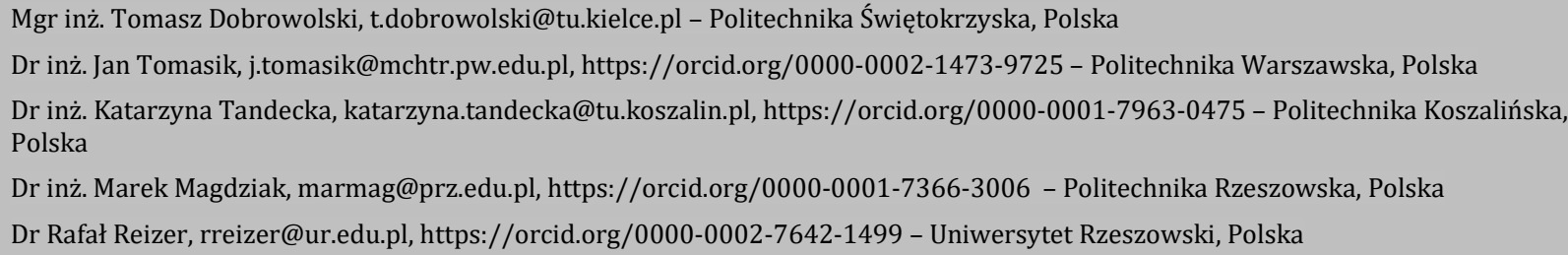

One of the sources of errors affecting the uncertainty of measurements of the surface texture is the measurement noise, called dynamic noise, which is a combination of the internal noise of the measuring instrument and the influence of the external environment. The article presents the comparison of measurement noise for instruments using various methods of measuring the surface texture that were used during the implementation of the project No. PBS2/A6/20/2013//NCBiR/24/10/2013 "Research and evaluation of reliability of modern methods of surface topography measurements in micro and nano scale".

KEYWORDS: measuring noise, optical measurements, contact measurements, surface texture

In recent years, there has been a rapid development of new methods for measuring the geometric structure of the surface, enabling the assessment of surface stereometry in both the micro- and nanoscale. Many publications have been written on the subject of measurement methods and evaluation [1-4]. The most commonly used methods of measuring surface stereometry are contact profilometry with a mapping blade, profilometry using confocal heads, coherent scanning interferometry, confocal microscopy and atomic force microscopy.

The obtained values of the surface geometrical structure parameters are influenced - regardless of the measurement method used - by many factors that are components of the measurement uncertainty. One of them is the measuring noise, which is a component of the output signal. Sources of its formation can be divided into those resulting from the principle of the device operation itself and from the impact of the external environment on the measurement process. The most important factors generating measuring noise include: instability of electronic systems, vibrations caused by mechanical drives, external vibrations at the place of the device installation, air movement caused by ventilation or air conditioning, and electromagnetic disturbances. Value and nature of the measurement noise depend on the design of the instrument and the measurement method used.

One of the methods of assessing the measuring noise of instruments for measuring the geometrical structure of the surface is to measure the AFL type standard (flat interference plate) $[5,6]$. Parameters that characterize the measuring noise value can be the square root of the ordinates of the primary profile $P q$ or the roughness profile $R q$ :

$$
P q, R q=\sqrt{\frac{1}{n} \sum_{i=1}^{n} z_{i}^{2}}
$$

where: $n$ - number of ordinates in the roughness profile, $z$ - value of the ordinate of the roughness profile. 
Surface measurements with low roughness are particularly sensitive to disturbing factors. It is therefore important to include noise value in the uncertainty budget of this type of measurement.

\section{Measurement results}

Measuring noise studies were carried out in several research centers in Poland. They were carried out on fourteen instruments for assessing the geometric structure of the surface, representing the first two classes of methods, in accordance with the classification system presented in PN-EN ISO 25178-6: 2011 [7], because they give the output in the form of a linear profile $z(x)$ or in the form of spatial topography $z(x, y)$. For the purposes of research-the instruments were divided into two groups: representing optical methods (symbol 0) and contact methods (symbol S). The list of devices and their symbols is included in tab. I.

\section{TABLE I. List of instruments used in the tests}

\begin{tabular}{|c|c|l|}
\hline No. & Instrument & \\
\hline 1. & 01 & Profilometric - confocal head, range $130 \mu \mathrm{m}$ \\
\hline 2. & 02 & Profilometric - confocal head, range $130 \mu \mathrm{m}$ \\
\hline 3. & 03 & Profilometric - confocal head, zakres $400 \mu \mathrm{m}$ \\
\hline 4. & 04 & Coherent correlation interferometry \\
\hline 5. & 05 & Profilometric - confocal head \\
\hline 6. & 06 & Laser confocal microscope \\
\hline 7. & S1 & Contact profilometry - induction head \\
\hline 8. & S2 & Contact profilometry - interferometer head \\
\hline 9. & S3 & Contact profilometry - interferometer head \\
\hline 10. & S4 & Contact profilometry - induction head \\
\hline 11. & S5 & Contact profilometry - optomechanical head \\
\hline 12. & S6 & Contact profilometry - induction head \\
\hline 13. & S7 & Contact profilometry - induction head \\
\hline 14. & S8 & Contact profilometry - induction head \\
\hline
\end{tabular}

During measurements of the geometric structure of the surface with the use of profilometric instruments using the AFL standard, due to the long time of these measurements, a clear impact of cyclic changes in ambient temperature on the results obtained was also observed, which was manifested by the occurrence of corrugation in the direction perpendicular to the axis of measurement [8]. This effect can be weakened by the use of thermal shields [9].

\section{Measurement of AFL type standard on atomic force microscope}

In order to check the geometrical structure of the AFL type standard, it was measured by means of an atomic force microscope using a SCANASYST-AIR type microbe (cantilever) (fig. 1). Basic dimensions of the microprobe blade according to the manufacturer's data are as follows: blade height $2.5 \div 8 \mu \mathrm{m}$, front angle $15 \pm 2.5^{\circ}$, rear angle $25 \pm 2.5^{\circ}$, nominal radius $2 \mathrm{~nm}$.

a)

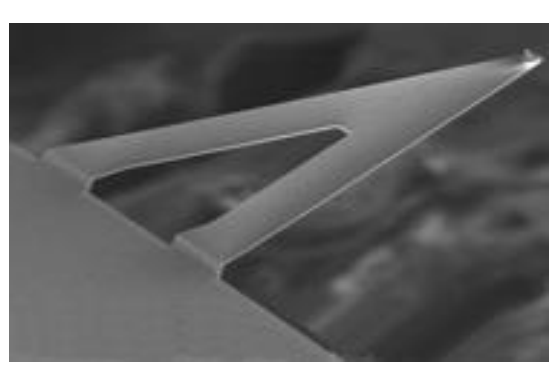

b)

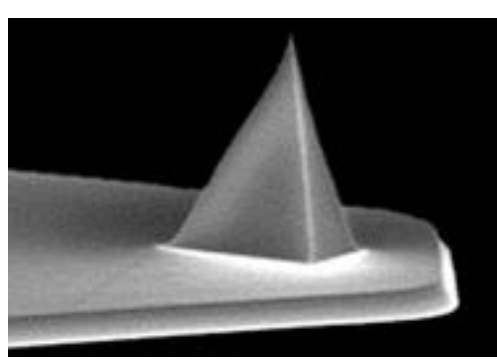

Fig. 1. SCANASYST-AIR micro-probe: a) lever, b) micro-probe blade (www.brukerafmprobes.com)

Measurement of the standard was carried out in the area of $90 \mu \mathrm{m} \times 90 \mu \mathrm{m}$, with the sampling interval $\Delta X=$ $\Delta Y=0.175 \mu \mathrm{m}$. The obtained isometric image of the pattern is shown in fig. 2 , while tab. II sets out the basic parameters of surface stereometry of the AFL standard. 


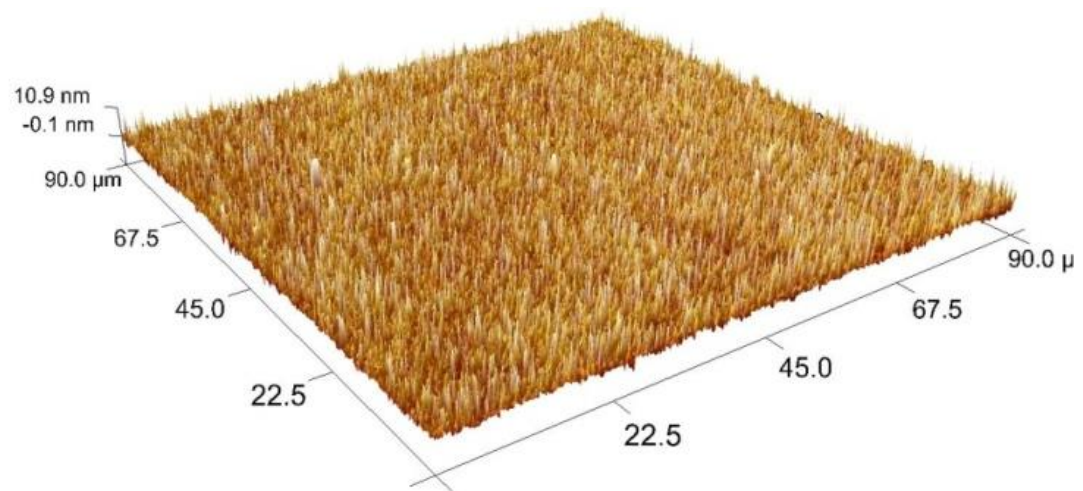

Fig. 2. Isometric image of the AFL type standard

TABLE II. Surface stereometry parameters of the AFL pattern

\begin{tabular}{|c|l|c|}
\hline Parameter & \multicolumn{1}{|c|}{ Description } & Value \\
\hline$S q, \mathrm{~nm}$ & Mean square surface deviation & 1.61 \\
\hline$S s k$ & Surface asymmetry & 1.60 \\
\hline$S k u$ & Surface kurtosis & 7.73 \\
\hline$S p, \mathrm{~nm}$ & Maximum peak height of the surface & 9.98 \\
\hline$S v, \mathrm{~nm}$ & Maximum depth of surface valley & 3.79 \\
\hline$S z, \mathrm{~nm}$ & Maximum surface height & 13.77 \\
\hline$S a, \mathrm{~nm}$ & Arithmetic mean surface deviation & 1.15 \\
\hline
\end{tabular}

Fig. 3 shows the ordinate distribution, the Abbott-Firestone curve, and the directional structure of the surface of the pattern. Five hundred and twelve profiles were extracted from the measured surface, for which the average values of basic parameters of the primary profile and the roughness profile were calculated using the Gauss filter $\lambda c=0.025 \mathrm{~mm}$ (tab. III). An example of a primary profile is shown in fig. 4 , and its frequency spectrum in fig. 5. Based on the analysis of the results, it can be concluded that geometrical structure of the AFL pattern is random, isotropic, with inequalities with an amplitude of several nanometers.

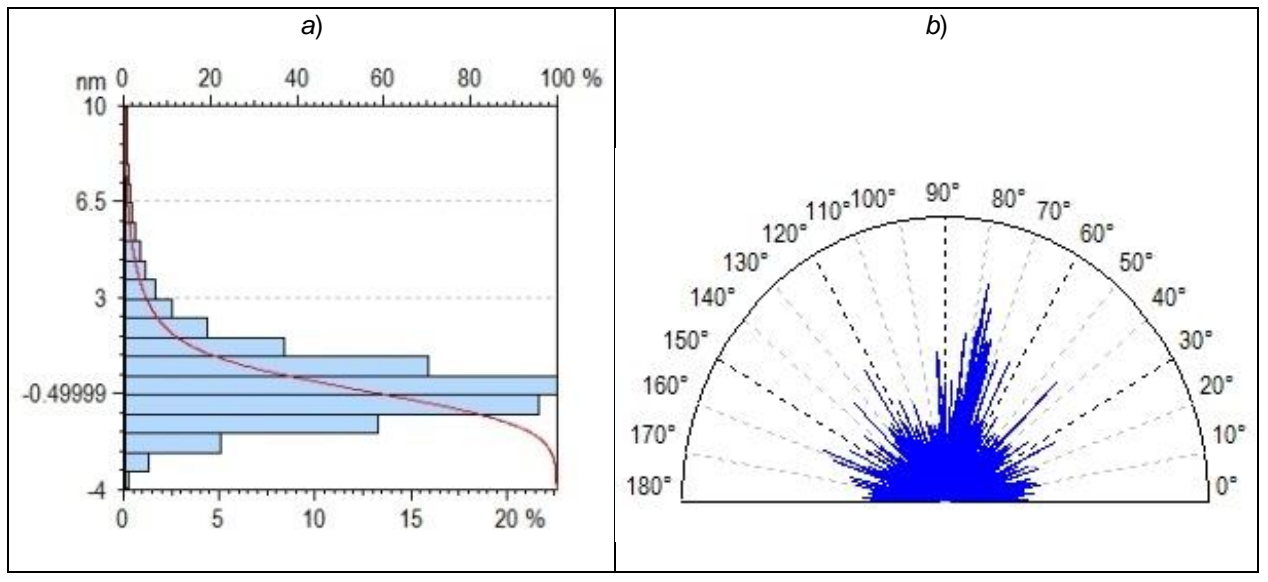

Fig. 3. AFL pattern: a) distribution of surface ordinates and Abbott-Firestone curve, b) structure directivity 
TABLE III. Average parameters of the AFL pattern profile

\begin{tabular}{|c|l|c|c|}
\hline Parameter & \multicolumn{1}{|c|}{ Description } & $\begin{array}{c}\text { Mean va- } \\
\text { lue }\end{array}$ & Standard deviation \\
\hline$P q, \mathrm{~nm}$ & $\begin{array}{l}\text { Mean square deviation of the prima- } \\
\text { ry profile }\end{array}$ & 1.6 & 0.12 \\
\hline$P S m, \mu \mathrm{m}$ & $\begin{array}{l}\text { Mean groove width of the primary } \\
\text { profile }\end{array}$ & 1.4 & 0.1 \\
\hline$R q, \mathrm{~nm}$ & $\begin{array}{l}\text { Mean square roughness profile de- } \\
\text { viation }\end{array}$ & 1.3 & 0.11 \\
\hline$R S m, \mu \mathrm{m}$ & $\begin{array}{l}\text { Mean width of roughness profile } \\
\text { grooves }\end{array}$ & 1.6 & 0.1 \\
\hline
\end{tabular}

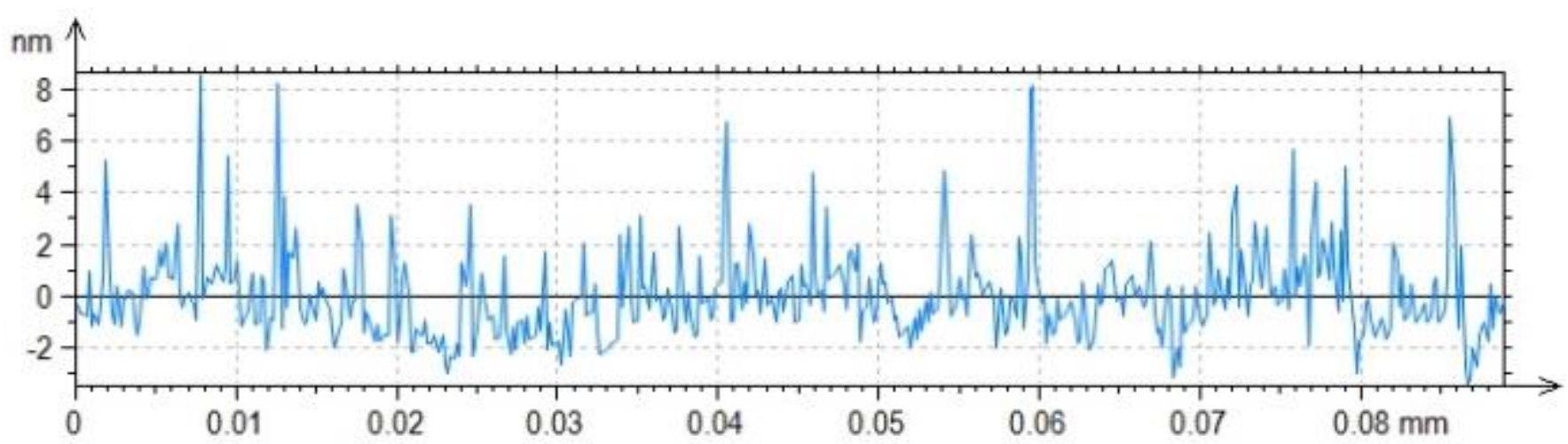

Fig. 4. Example of extracted primary profile

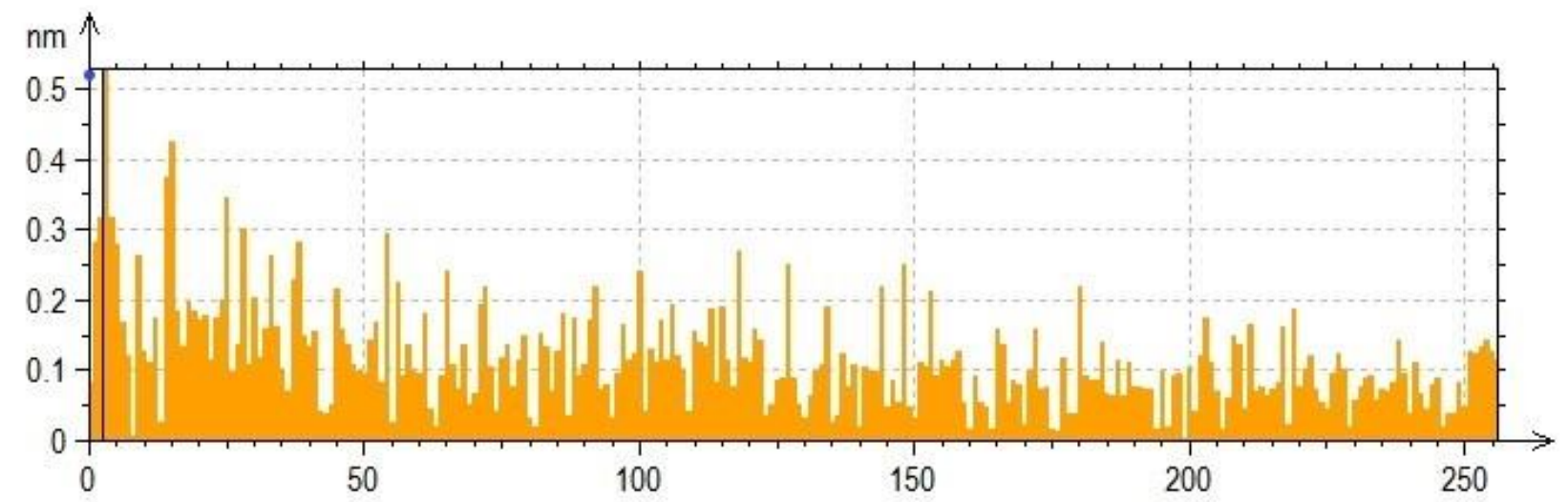

Wave length \#2 $(0.045088 \mathrm{~mm})$

Size $: 0.31852 \mathrm{~nm}$

Fig. 5. Frequency spectrum of the extracted primary profile

\section{Investigation of the influence of the mapping blade feedrate on the measuring noise value}

An important parameter that should be selected before measuring with a contact profilometer is the speed of the mapping blade. In order to determine the influence of the tip feedrate of the measuring tip on the value of the measuring noise, measurements of the AFL type standard were performed. For this purpose, a contact profilometer with an interferometric head was used, equipped with a measuring tip in the form of a $2 \mu \mathrm{m} \mathrm{di-}$ amond needle with a $90^{\circ}$ cone angle. The sampling interval was $\Delta X=0.125 \mu \mathrm{m}$. Measurements were made for the following speed of the mapping blade $v: 0.1 ; 0.25 ; 0.5 ; 1 ; 2 \mathrm{~mm} / \mathrm{s}$.

Fig. 6 shows the obtained roughness profiles for selected mapping blade feedrates. Tab. IV, however, contains values of $P q$ and $R q$ parameters (after applying a Gaussian filter $\lambda c=0.08 \mathrm{~mm}$ ) depending on the feedrate of the mapping blade. 

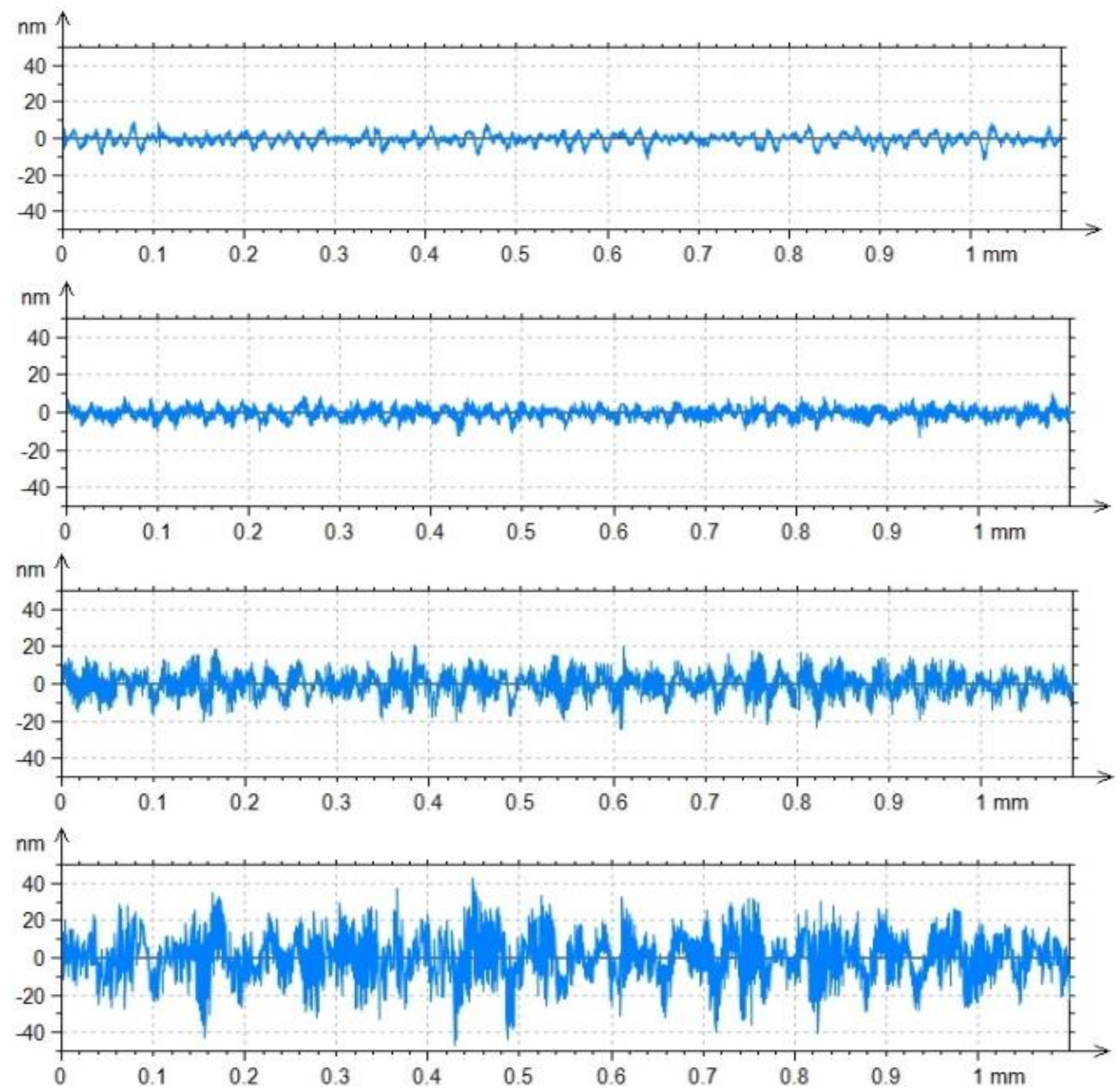

Fig. 6. Roughness profiles obtained for the mapping blade feedrate: a) $v=0.1 \mathrm{~mm} / \mathrm{s}, \mathrm{b}) v=0.5 \mathrm{~mm} / \mathrm{s}, \mathrm{c}$ ) $v=1.0 \mathrm{~mm} / \mathrm{s}, \mathrm{d}) v=2.0 \mathrm{~mm} / \mathrm{s}$

TABLE IV. Values of the parameters of the primary profile and roughness profile for the AFL pattern depending on the mapping blade feedrate

\begin{tabular}{|l|c|c|c|c|c|}
\hline$v, \mathrm{~mm} / \mathrm{s}$ & 0.1 & 0.25 & 0.50 & 1.0 & 2.0 \\
\hline$P q, \mathrm{~nm}$ & 3.6 & 3.6 & 3.7 & 7.0 & 14.1 \\
\hline$R q, \mathrm{~nm}$ & 2.9 & 2.6 & 2.9 & 6.4 & 12.8 \\
\hline
\end{tabular}

Based on the results obtained, it can be stated that up to the feedrate $v=0.5 \mathrm{~mm} / \mathrm{s}$, the value of measuring noise remains constant, while for velocity $v=2 \mathrm{~mm} / \mathrm{s}$, it is almost four times higher.

\section{Comparative measurements of measuring noise}

Comparative measurements of measuring noise were carried out for six optical instruments and eight contact instruments. The measuring section with a length of $1.25 \mathrm{~mm}$ was analyzed. Roughness profiles after the application of the Gaussian filter $\lambda c=0.08 \mathrm{~mm}$, obtained for optical and contact instruments respectively, are shown in figs. 7 and 8. 

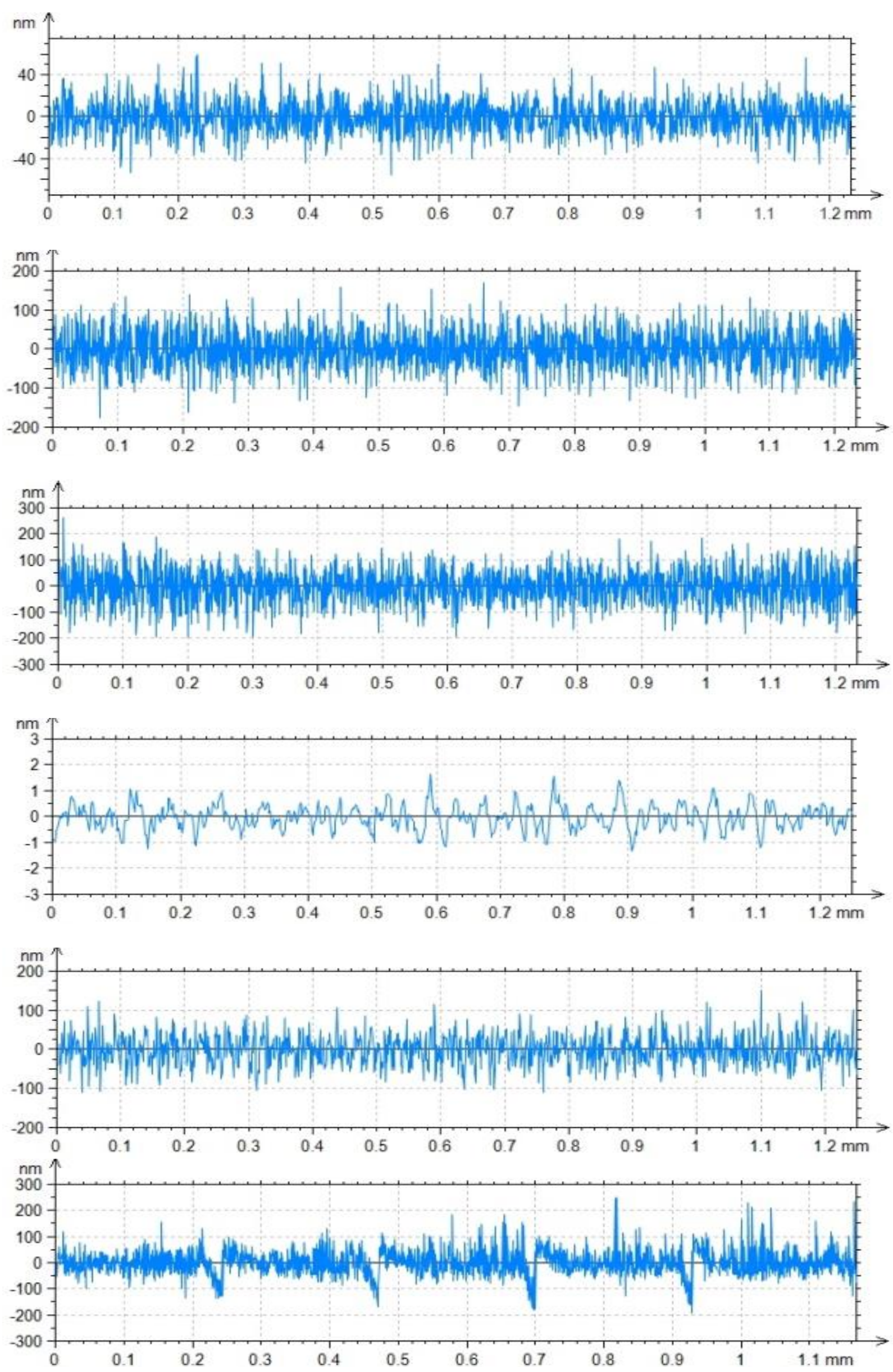

Fig. 7. Roughness profiles of the AFL pattern obtained when using optical instruments 

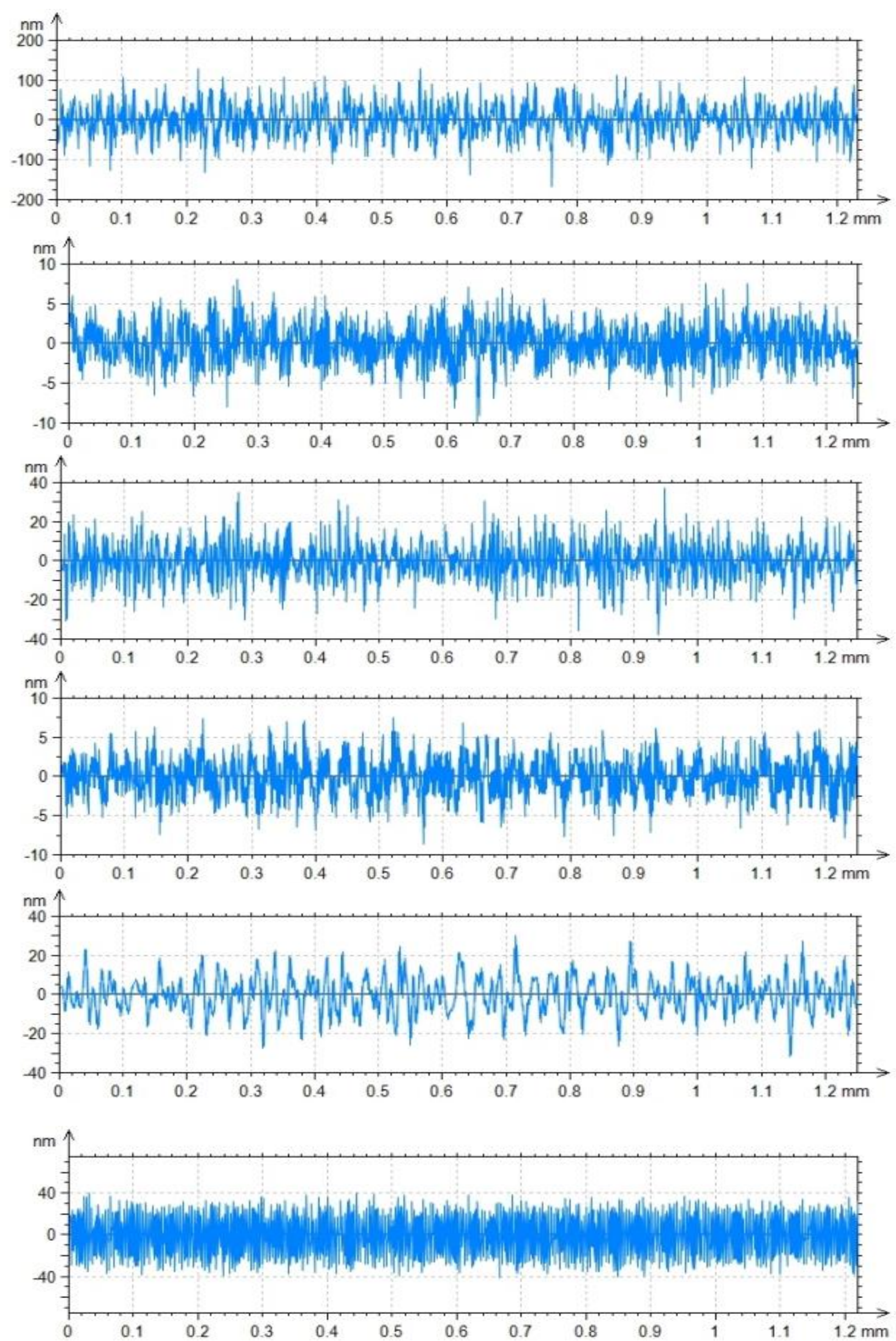


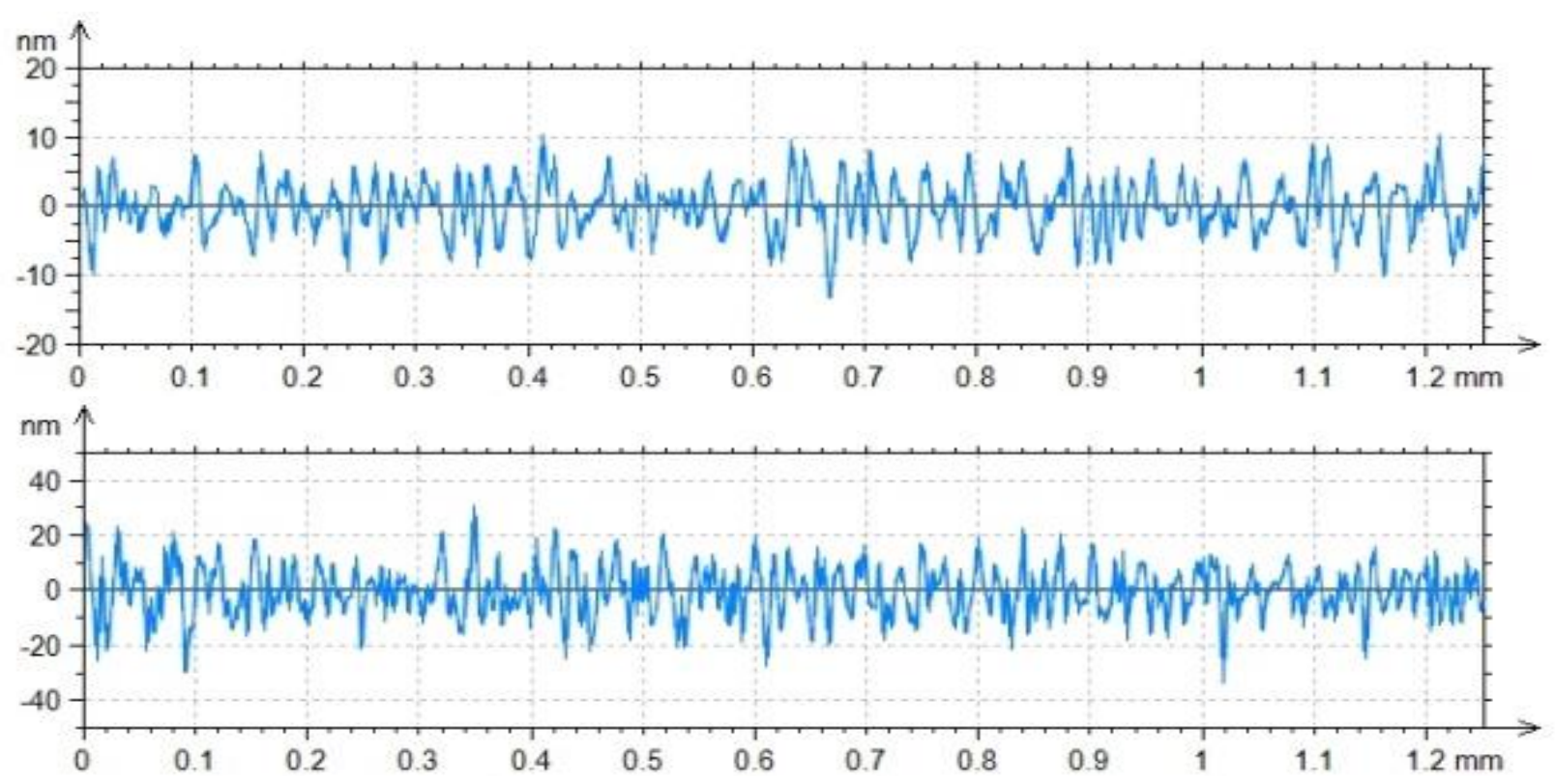

Fig. 8. Roughness profiles of the AFL pattern obtained when using contact instruments

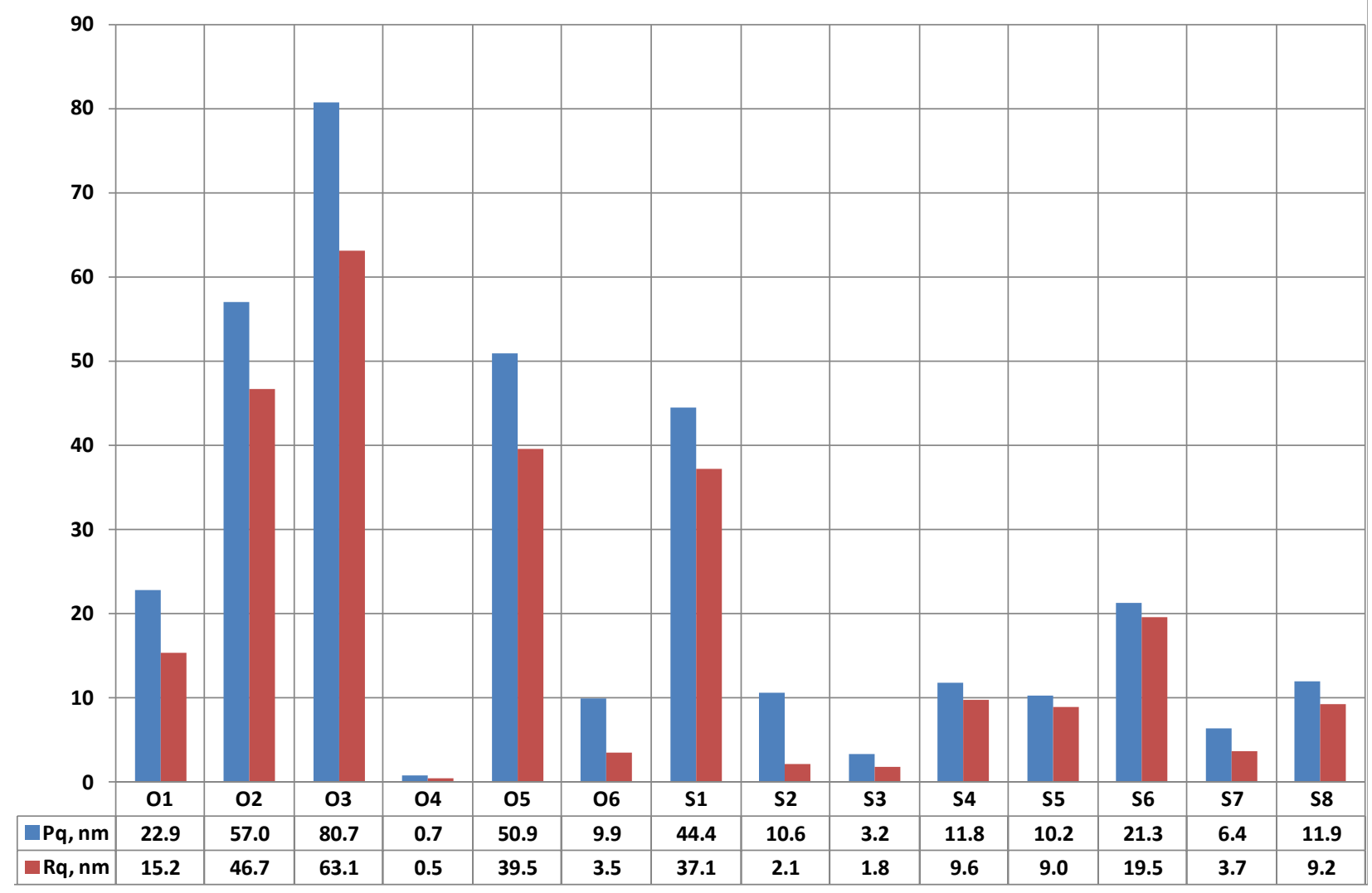

Fig. 9. List of measuring noise ( $P q$ and $R q$ parameters) for optical and contact devices

Fig. 9 presents values of $P q$ and $R q$ parameters obtained when using optical and contact devices.

Optical instruments $01,02,03$ and 05 as well as the S1 contact device are profilometric devices, in which the feedrate is carried out by the $X Y$ table. In their case, the highest measuring noise values were obtained. The distribution of the ordinates of the measured profile on the AFL standard is usually similar to the normal distribution. The exception is even distribution profile obtained with the S6 contact device.

\section{Summary}

The study showed that of all instruments, the 04 optical device using the method of coherent correlation interferometry is characterized by the lowest measuring noise value. The measured values of $P q$ and $R q$ are 
even smaller than when using the atomic force microscope. This may be due to the fact that the sampling distance for this instrument was $\Delta X=1.66 \mu \mathrm{m}$, i.e. it was more than ten times larger than for the atomic force microscope.

Among the contact devices, the smallest values of measuring noise are characteristic for S2 and S3 devices, equipped with interferometric heads.

The highest measuring noise values are characterized by optical instruments 01, 02, 03 and 05, equipped with confocal heads, and an S1 contact device with an induction head. The high noise figure for these instruments is due to the fact that the horizontal axis feedrate is realized by the $X Y$ measuring table.

For the 06 instrument, i.e. the confocal laser microscope, periodic disturbances can be observed on the roughness profile, resulting from errors in joining individual measurements due to the need for using the stitching function suitable for optical instruments.

Conducted tests confirmed that for many instruments, measuring noise is a significant component of the uncertainty budget of the measurements of the surface geometric structure. For this reason, it is advisable to check noise to ensure reliable measurements.

The paper was based on the results obtained during the implementation of project No. PBS2/A6/20/2013 "Research and assessment of the reliability of modern methods of measuring surface topography at the micro and nano scale", financed by the National Center for Research and Development.

The paper was financed as part of a project implemented by Fabryka Montażów Tocznych - Kraśnik S.A., financed from the European Union's "Intelligent Development" operational program.

\section{REFERENCES}

[1] Wiśniewska M., Tomasik. J., Żebrowska-Łucyk S. „Metody cyfrowej filtracji wyników pomiarów SGP według norm z serii ISO 16610". Mechanik. 87, 12 (2014): 1024-1027.

[2] Kacalak W., Tandecka K., Mathia T.G. "A method and new parameters for assessing the active surface topography of diamond abrasive films". Journal of Machine Engineering. 16, 4 (2016).

[3] Wdowik R., Magdziak M., Porzycki J. "Measurements of surface roughness in ultrasonic assisted grinding of ceramic materials". Applied Mechanics and Materials. 627 (2014): 191-196.

[4] Pawlus P., Reizer R., Wieczorowski M. "The analysis of directionality of honed cylinder liners surfaces". Scanning. 36, 1 (2014): 95-104.

[5] PN-EN ISO 25178-70:2014 SGP przestrzenna - Część 70: Wzorce materialne.

[6] Giusca Claudiu L., Leach Richard K. "Good Practice Guide No. 129. Calibration of the metrological characteristics of areal contact stylus instruments".

[7] PN-EN ISO 25178-6:2011 Specyfikacje geometrii wyrobów (GPS) -Struktura geometryczna powierzchni: Przestrzenna - Część 6: Klasyfikacja metod pomiaru struktury geometrycznej powierzchni.

[8] Miller T., Adamczak S., Świderski J., Wieczorowski M., Łętocha A., Gapiński B. "Influence of temperature gradient on surface texture measurements with the use of profilometry". Bulletin of the Polish Academy of Sciences. 65, 1 (2017): 53-61.

[9] Adamczak S., Świderski J., Dobrowolski T. "Wpływ zastosowania osłony termicznej profilometru stykowego na wyniki pomiarów stereometrii powierzchni". Mechanik. 2 (2018): 126-128. 